\title{
INVESTIGATION OF THE ENERGY POTENTIAL FROM TIDAL STREAM CURRENTS IN INDONESIA
}

\author{
Kadir Orhan ${ }^{1}$, Roberto Mayerle ${ }^{1}$, Rangaswami Narayanan ${ }^{1}$ and Wahyu Widodo Pandoe ${ }^{2}$
}

\begin{abstract}
In this paper, an advanced methodology developed for the assessment of tidal stream resources is applied to several straits between Indian Ocean and inner Indonesian seas. Due to the high current velocities up to 3-4 $\mathrm{m} / \mathrm{s}$, the straits are particularly promising for the efficient generation of electric power. Tidal stream power potentials are evaluated on the basis of calibrated and validated high-resolution, three-dimensional numerical models. It was found that the straits under investigation have tremendous potential for the development of renewable energy production. Suitable locations for the installation of the turbines are identified in all the straits, and sites have been ranked based on the level of power density. Maximum power densities are observed in the Bali Strait, exceeding around $10 \mathrm{kw} / \mathrm{m}^{2}$. Horizontal axis tidal turbines with a cut-in velocity of $1 \mathrm{~m} / \mathrm{s}$ are considered in the estimations. The highest total extractable power resulted equal to about $1,260 \mathrm{MW}$ in the Strait of Alas. Preliminary assessments showed that the power production at the straits under investigation is likely to exceed previous predictions reaching around 5,000MW.
\end{abstract}

Keywords: renewable energy; tidal stream currents; numerical model; Indonesia

\section{INTRODUCTION}

The global energy supply is facing severe challenges in terms of long-term sustainability, fossil fuel reserve exhaustion, global warming and other energy related environmental concerns, geopolitical and military conflicts surrounding oil rich countries, and secure supply of energy. Renewable energy sources such as solar, wind, wave and tidal energy are capable of meeting the present and future energy demands with ease without inflicting any considerable damage to global ecosystem (Asif et al. 2007). Carbon dioxide emissions from electricity generation, especially from burning fossil fuels, are a major cause of anthropogenic climate change, and growing concern over the threat of climate change has led to an increased interest in research and development of renewable energy technologies.

The ocean provides a vast source of potential energy resources, and the conversion of tidal current power is recently growing up to a crucial sector of renewable ocean energy. Although in the recent years modelling approaches have become more sophisticated and have been performed for many regions in the world to identify prospective locations for tidal stream farms, lack of reliable data necessary for the assessments, particularly in more remote areas, causing major limitations for investigations. In order to improve the reliability of the information concerning the potential of tidal stream resources, it is essential to improve resource characterization and rationale for site selection.

Indonesia has various potential sources for renewable energy production; nevertheless the percent of the renewable energy contribution in primary energy mix is currently very low. The development of renewable energy in Indonesia is regulated by a Presidential Decree which states that the contribution of renewable energy should be increased to $17 \%$ of the total national primary energy mix by 2025 , which includes the wave and tidal energy. The decree also states that efforts, including research, should be intensified to reach this goal (Blunden et al. 2013).

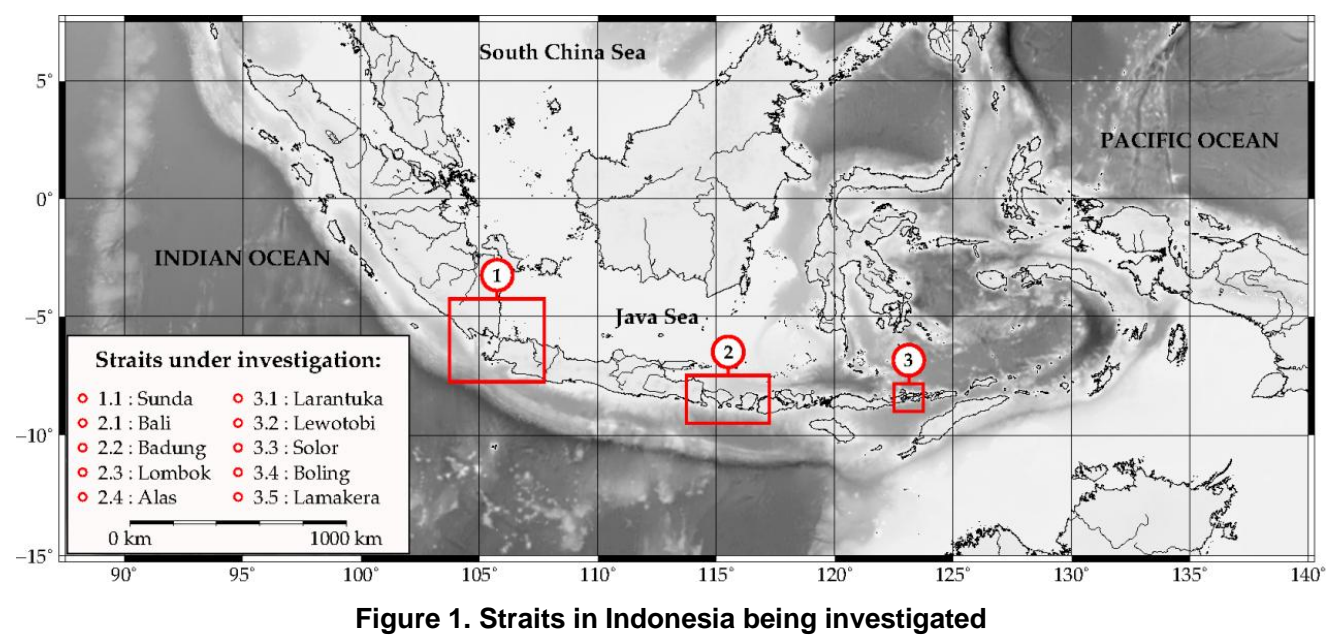

\footnotetext{
${ }^{1}$ Research and Technology Centre Westcoast (FTZ), Otto-Hahn-Platz 3, Kiel 24118, Germany

${ }^{2}$ Agency for the Assessment and Application of Technology (BPPT), Indonesia
} 
In order to install the technology to capture ocean renewable energy, however, it may be necessary to mitigate conflict with existing ocean space users. To this end, involving stakeholders from various fields in the development process, and taking policy issues and existing zoning plans into account is of utmost importance. Otherwise, particularly in the districts like Alas and Bali where coastal areas are being used for a wide range of activities such as aquaculture, fishing and tourism, it is inevitable to face major problems.

In this paper, results of the tidal stream resource assessment performed for the straits between Indian Ocean and inner Indonesian seas (Figure 1) are presented. The investigations have been carried out in the framework of joint research project "Potentials of Ocean Renewable Energy in the Indonesian Seas - ORE-12" funded by the German Ministry of Education and Research. The project aimed at the identification of marine environments in the Indonesian Archipelago, which are suitable for the efficient generation of electric power by tidal in-stream energy conversion (TISEC) devices and wave converters. As the overall goal of ORE-12, a "Decision Support System (DSS)" to process, to analyze and to evaluate the results of the numerical simulations of flow, and to estimate the tidal stream power potentials in order to identify best sites for the use of ocean renewable energy is established and currently being improved.

\section{METHODOLOGY and APPLICATION}

A stepwise methodology comprising the modelling of tidal stream currents, selection of suitable sites for the converters, resource assessment and estimation of the power potentials is followed (Orhan et al. 2015). The methodology is applied to the straits indicated in figure 1: Sunda, Bali, Badung, Lombok, Alas, Lamakera, Boling, Solor, Lewotobi and Larantuka. The straits are located between islands starting from Sumatra in the west till Lembata in the east. They link Indian Ocean and Savu Sea in the south, to Java Sea, Bali Sea and Flores Sea in the north. The Strait of Larantuka is the shortest strait with a $3 \mathrm{~km}$ length, and it is also the narrowest one with a $650 \mathrm{~m}$ width at its bottleneck. Alas Strait, with a $75 \mathrm{~km}$ length, is the longest strait, and Sunda Strait is the widest, with a $30 \mathrm{~km}$ width at its narrowest section. Complicated coastal geometries, countless small islands, rugged bottom topography next to wide shelves of shallow water, and large quantities of tidal power input from the adjoining Indian and Pacific oceans, all combine to form complex systems within these domains (Ray et al. 2005). While predicted tidal ranges diversify between $1 \mathrm{~m}$ and $3 \mathrm{~m}$, tidal currents typically have peak velocities during spring tides, exceeding $4 \mathrm{~m} / \mathrm{s}$. Moreover, exchange of water and heat from the Pacific Ocean to the Indian Ocean occurs through Indonesian Throughflow (ITF), which is the only natural connection between two tropical oceans on Earth. A minor portion of the ITF is being transported through the Lombok Strait as a subsurface jet (Mayer et al. 2012). Flow conditions on Sunda Strait are also affected by the regional excess of freshwater entering into Pacific waters through Sunda Shelf (Gordon 2005).

\section{Modelling of tidal currents}

Tidal stream currents are computed with the Delft3D Modelling System, developed by Deltares, the Netherlands. 3D models with fixed layers in depth wise direction were developed. Grids were constructed with a resolution up to $20 \mathrm{~m}$ in horizontal and $3 \mathrm{~m}$ in vertical. Computational grids used for simulations, and the nesting sequence comprising of two models set up for the Strait of Larantuka are illustrated in figure 2. Bathymetric data for the Strait of Larantuka have been obtained from single beam echo sounding surveys, and for the rest, data have been obtained from SRTM15_PLUS, a data fusion of global seafloor topography from satellite altimetry and ship depth soundings. Much attention has been given to the meteorological forcing and conditions at the open sea boundaries to adequately capture the density gradients and flow fields along the straits. Tidal forcing is extracted from TPXO Indian Ocean Atlas ( $1 / 12^{\circ}$ regional model). 11 harmonic constituents (M2, S2, N2, K2, K1, O1, P1, Q1, M4, MS4 and MN4) were considered in this study. Data to determine the sea surface height, salinity and temperature at the open sea boundaries are supplied from HAMSOM, the Hamburg Shelf Ocean Model, which is a 3D free surface baroclinic hydrodynamic model developed in the Institute of Oceanography at the University of Hamburg. Data from Global Forecast System of NOAA's National Climatic Data Center have been used as meteorological input. Thus, effects of air cloudiness, air temperature, atmospheric pressure, relative air humidity and wind (in $\mathrm{E}$ and $\mathrm{N}$ directions) have been considered in simulations. 
Model verifications using tidal records shows excellent agreement. Location of an operational measuring device is indicated in figure 2, and figure 3 shows comparisons of modelled values and the values measured by the indicated device, from 1 to 31 of July 2014. The agreement between modelled and measured values was tested with the Pearson's product moment correlation coefficient. The $r$ value was resulted equal to 0.98 , which indicates a strong, positive linear relationship.
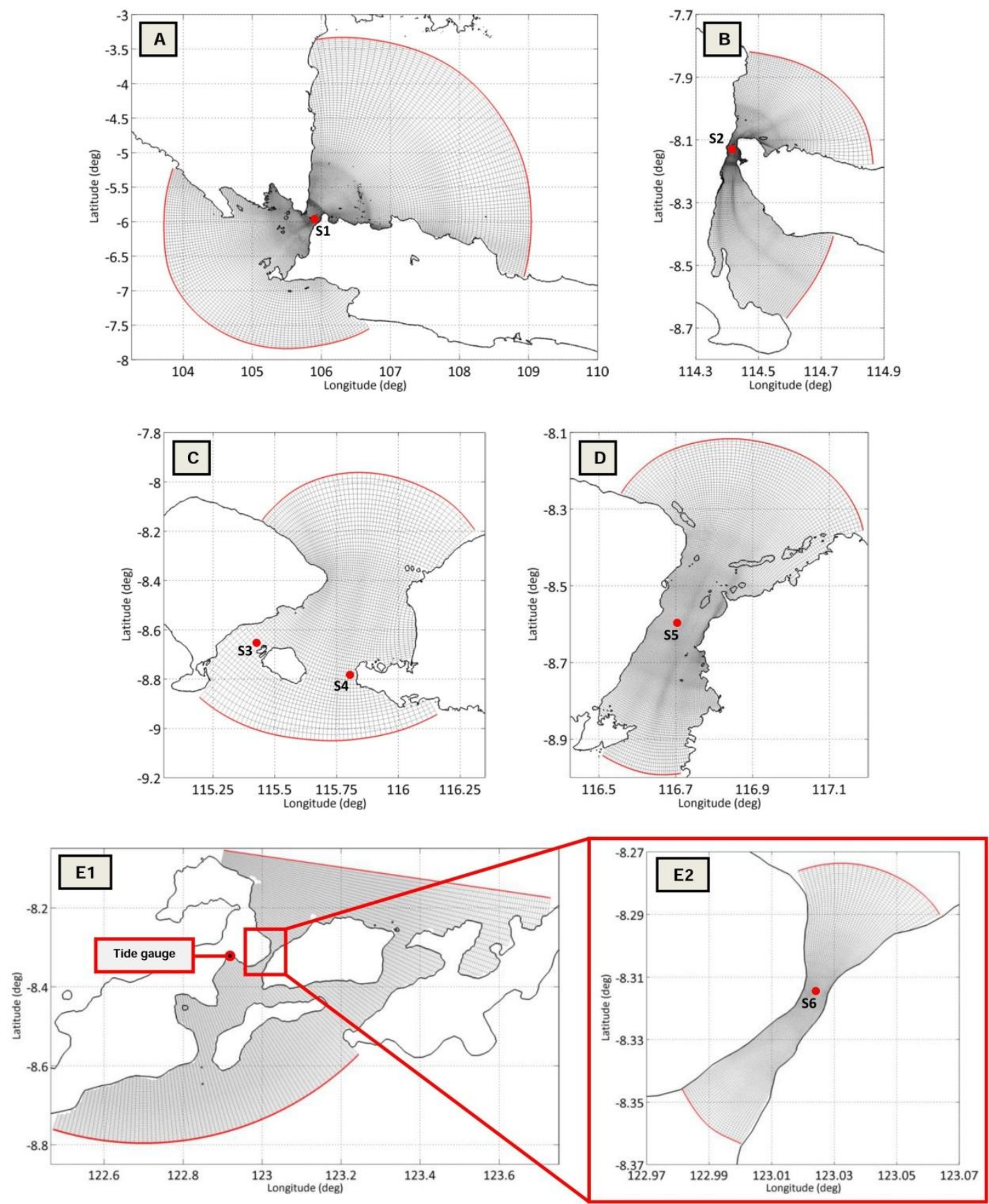

Figure 2. Computational grids of numerical models (A: Sunda Strait, B: Bali Strait, C: Badung \& Lombok straits, D: Alas Strait, E1 [Overall Model]: Lamakera, Boling, Solor, Lewotobi and Larantuka straits, E2 [Detailed Model]: Strait of Larantuka), and the nesting sequence comprising of two models set up for the Strait of Larantuka 


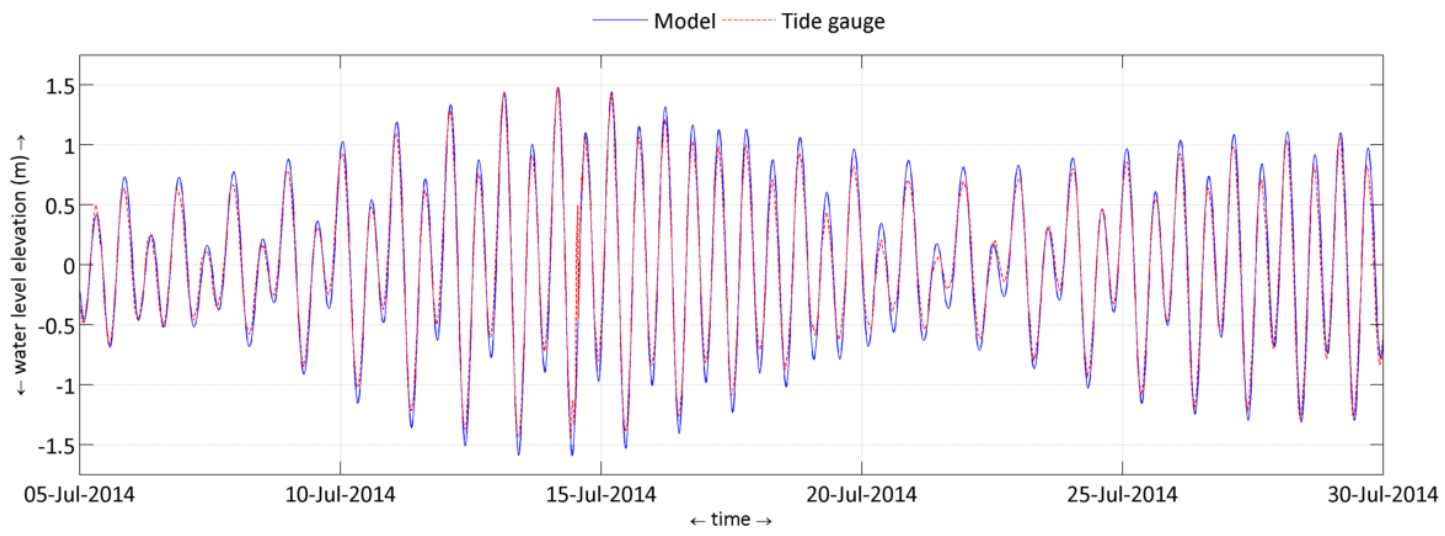

Figure 3. Comparison of measured and modelled tidal water levels $(r=0.98)$

\section{Suitability criteria and energy hotspots}

Site selection for the installation of TISEC devices depends on available power, site characteristics, and possible environmental and socio-economic impacts of the projects (Defne et al. 2011). In this study, a multi-criteria assessment methodology that accounts for physical constraints is applied to determine suitable locations for tidal stream power conversion. Horizontal axis tidal turbines which can harness a strongly bi-directional flow are considered in the evaluations. The near free surface upper $5 \mathrm{~m}$ is eliminated for recreational activities (small boats, swimmers, etc.) and to minimize turbulence and wave loading effects on the turbines, as well as damage from floating materials (EMEC 2009). At the bottom, the turbines are located above the low-speed benthic boundary layer, which is usually $10 \%$ of the mean lower low water depth (EPRI 2006). Considering these clearances, minimum depth is defined as $7.5 \mathrm{~m}$, which is adequate to install a turbine with a rotor diameter of $1.5 \mathrm{~m}$. Average kinetic power densities in the region have been estimated as follows:

$$
P=\frac{1}{2} \cdot \rho \cdot U^{3}
$$

where $P$ is tidal stream power per unit area of flow $\left(\mathrm{kW} / \mathrm{m}^{2}\right), \rho$ is the density of sea water $\left(\mathrm{kg} / \mathrm{m}^{3}\right)$ and $U$ is the current velocity $(\mathrm{m} / \mathrm{s})$. Generally, TISEC devices require a minimum flow velocity (cut-in velocity) to start operating, which ranges from $0.5 \mathrm{~m} / \mathrm{s}$ to $1 \mathrm{~m} / \mathrm{s}$ depending on their design (EPRI 2006). Considering also this limitation, regions with the average kinetic power density larger than $0.5 \mathrm{~kW} / \mathrm{m}^{2}$ (corresponding to a current velocity of $1 \mathrm{~m} / \mathrm{s}$ ), surface area larger than $0.5 \mathrm{~km}^{2}$ and water depths larger than $7.5 \mathrm{~m}$ are defined as energy hotspots, suitable locations for tidal stream power conversion.

Modelled tidal stream current velocities, taken from observation stations S1, S2, S3, S4, S5 and S6 (Figure 2) are shown in figure 4. Figure 5 shows the spatial variation of the average kinetic power densities at the energy hotspots within investigated domains.

Regarding the identification of suitable locations for tidal stream power conversion, future research efforts should be widened to accommodate conflicting use of marine environment such as fishing, shipping, offshore wind, habitat protection and also technical limitations. Comprehensive life cycle assessments of power converter arrays that would also include areas like fluctuation of power output, storage, or grid integration are still missing (Uihlein 2016). In this study, a methodology is currently being developed to take main environmental constraints and accessibility of the resources into account alongside physical constraints. Moreover, the intersectorial Zoning Plan for Marine, Coast and Small islands proposed by the Directorate General of Coastal Zones and Small Islands shall be accounted for. The scheme envisages the reduction of conflicts with other activities and stakeholders, and defines guidelines and activities, which are allowed, permitted with license, and/or prohibited in the region under consideration. 
S1 - Sunda Strait
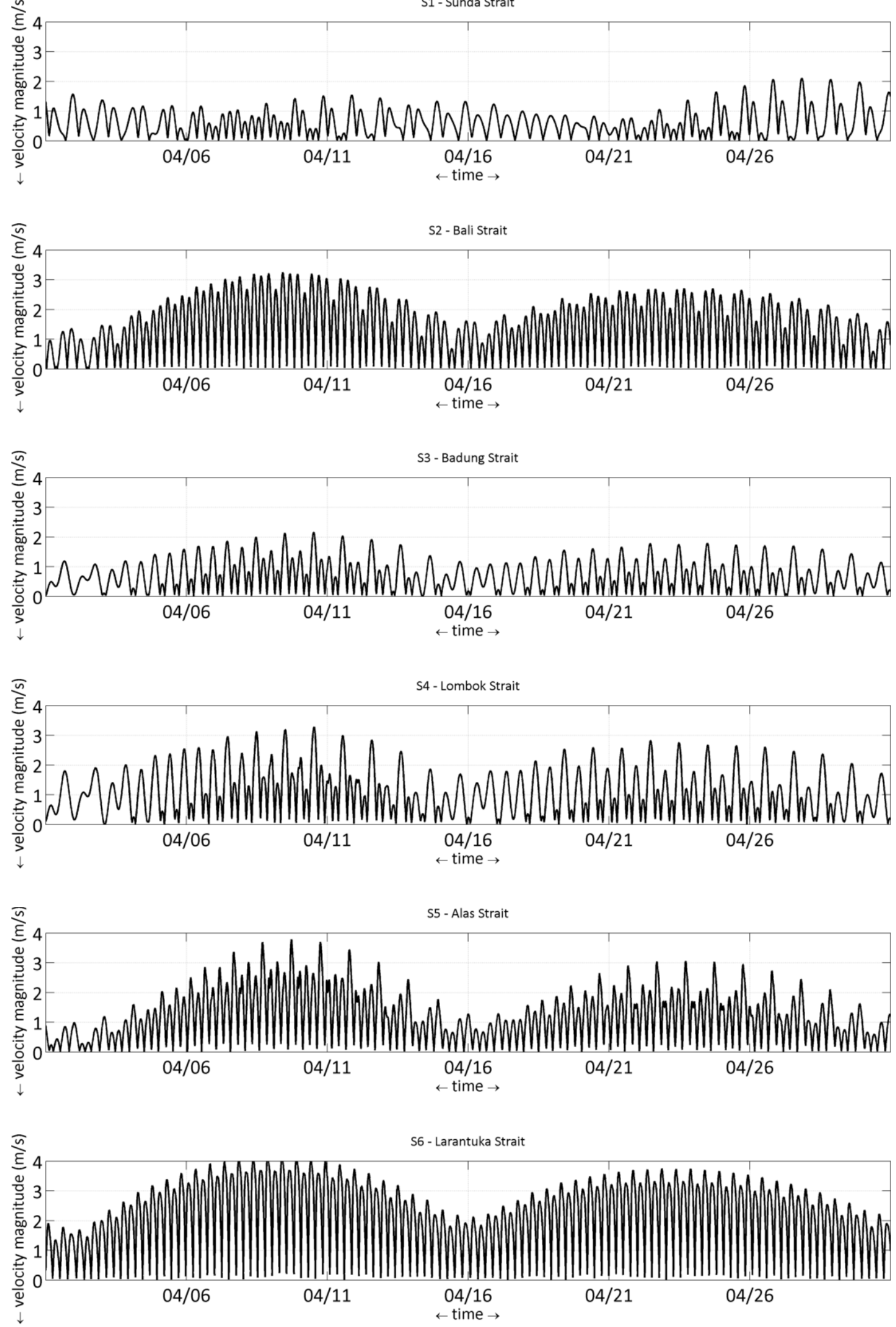

Figure 4. Modelled depth averaged tidal stream current velocities $(01.04 .2012-30.04 .2012)$ 

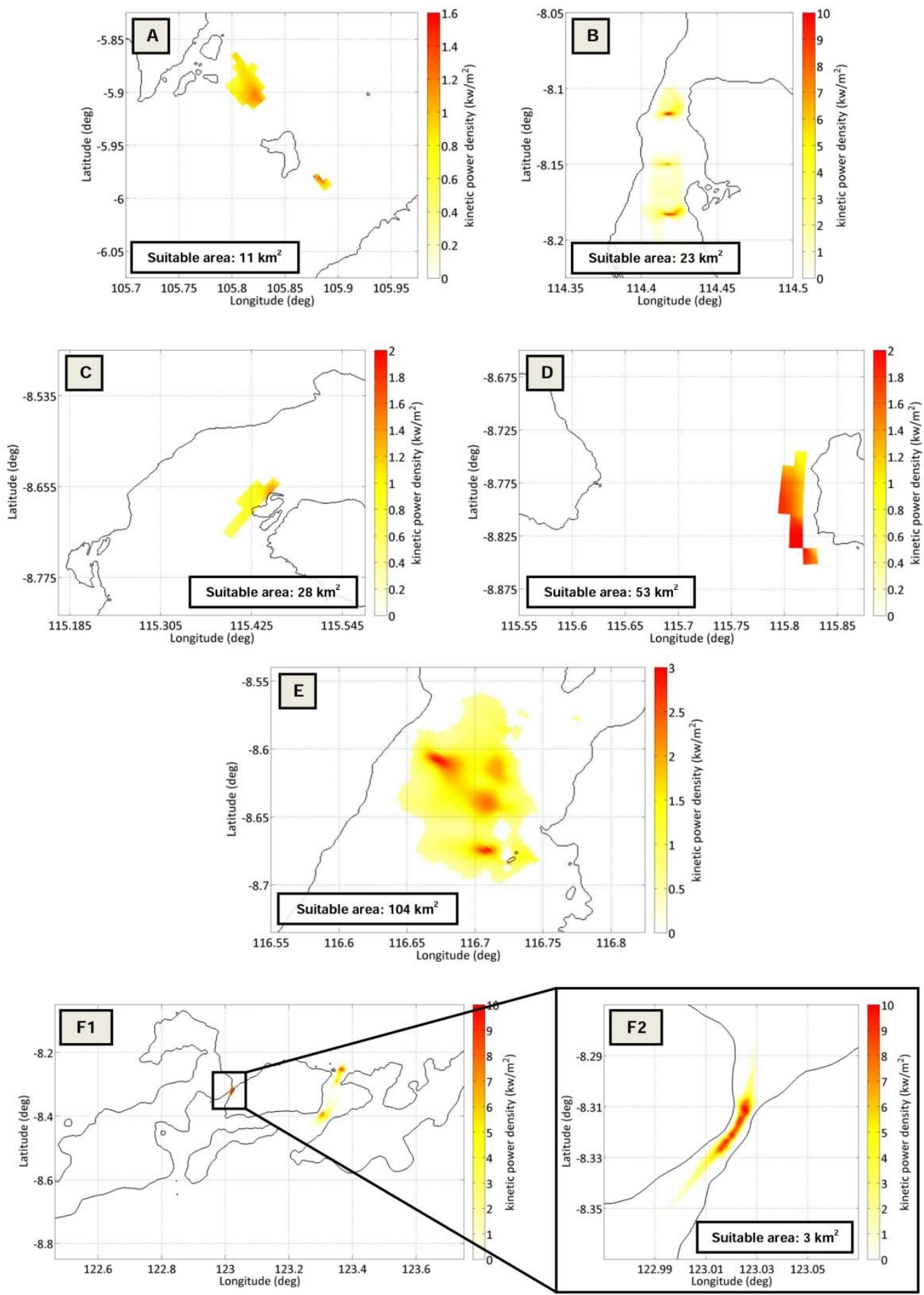

Figure 5. Spatial variation of the average kinetic power densities in the energy hotspots within investigated domains (A: Sunda Strait, B: Bali Strait, C: Badung Strait, D: Lombok Strait, E: Alas Strait, F1: Lamakera, Boling, Solor, Lewotobi and Larantuka straits, F2: Strait of Larantuka) 


\section{Resource assessment and tidal stream power potentials}

To compute the exploitable power densities using tidal turbines, current velocities at the hub heights of the turbines have been used and rated flow velocities of the turbines have been neglected. Considering a chain of water to wire efficiencies, the electric power that can be delivered to the local grid by each turbine was estimated using:

$$
P_{\text {electric }}=A_{\text {turbine }} \cdot \frac{1}{2} \cdot \rho \cdot U_{\text {hub }}{ }^{3} \cdot \eta_{\text {turbine }} \cdot \eta_{\text {ptake-off }}
$$

where $A_{\text {turbine }}$ is turbine rotor swept area $\left(\mathrm{m}^{2}\right)$ and $U_{\text {hub }}$ is current velocity magnitude at the turbine hub height $(\mathrm{m} / \mathrm{s}) . \eta_{\text {turbine }}(=45 \%)$ is the efficiency with which the turbine extracts kinetic energy from the incoming flow, and $\eta_{\text {ptake-off }}$, power take-off efficiency, was given using equation (3).

$$
\eta_{\text {ptake-off }}=\eta_{\text {drivetrain }} \cdot \eta_{\text {generator }} \cdot \eta_{\text {pcon }}
$$

where $\eta_{\text {drivetrain }}(=96 \%)$ is the efficiency with which the energy extracted from the flow is delivered to the generator, $\eta_{\text {generator }}(=95 \%)$ is the efficiency with which the mechanical energy input to the generator is converted to electricity and $\eta_{p c o n}(=98 \%)$ is the efficiency with which the electricity produced by the generator is conditioned to meet phase and voltage requirements of the local electrical grid interconnection point (EPRI 2006). Analysis showed that the turbines with rotor diameters ranging between $1.5 \mathrm{~m}$ to $20 \mathrm{~m}$ are suitable for installation in identified energy hotspots. Examples for power curves used to compute the expected turbine output power are shown in figure 6.

Considering the criteria described in the previous section and estimated power curves for the tidal turbines, distributions of the applicable tidal turbine rotor diameters within the Strait of Larantuka is shown as an example in figure 7A, and figure 7B shows the spatial variation of the estimated electric power that can be delivered to local electrical grid by turbines. It can be seen that the resulting density of the extractable electric power corresponds more with current velocities than with rotor diameter. At the locations where the current velocities are higher, extractable electric power density can exceed about 1,200MW.

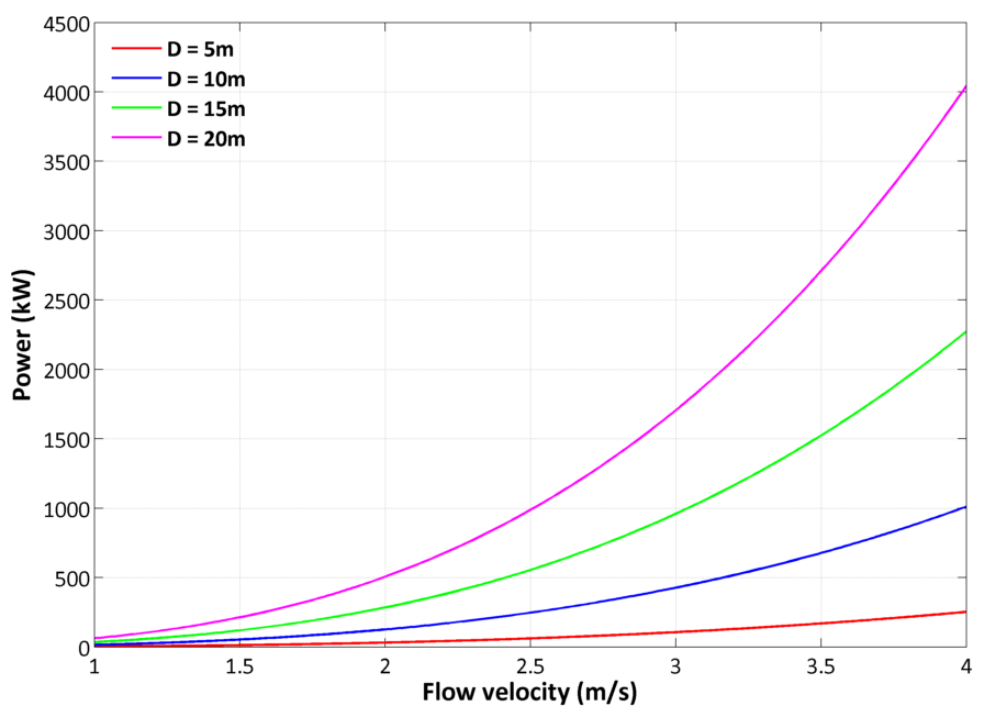

Figure 6. Power curves for tidal turbines with the rotor diameters (D) of 5, 10, 15, 20 meters

Table 1 shows the results of the tidal stream resource assessment, and ranking of the investigated domains based on the level of kinetic power densities. The total extractable powers were calculated based on a variation of the "per-generator" method (Blunden et al. 2013). The extracted energy is calculated from the flow fields in their natural states, considering the size and performance of the devices and packing density within the energy hotspots. The wake effects of turbines have been ignored, avoided by setting the spacing among generators to minimize the interferences. 

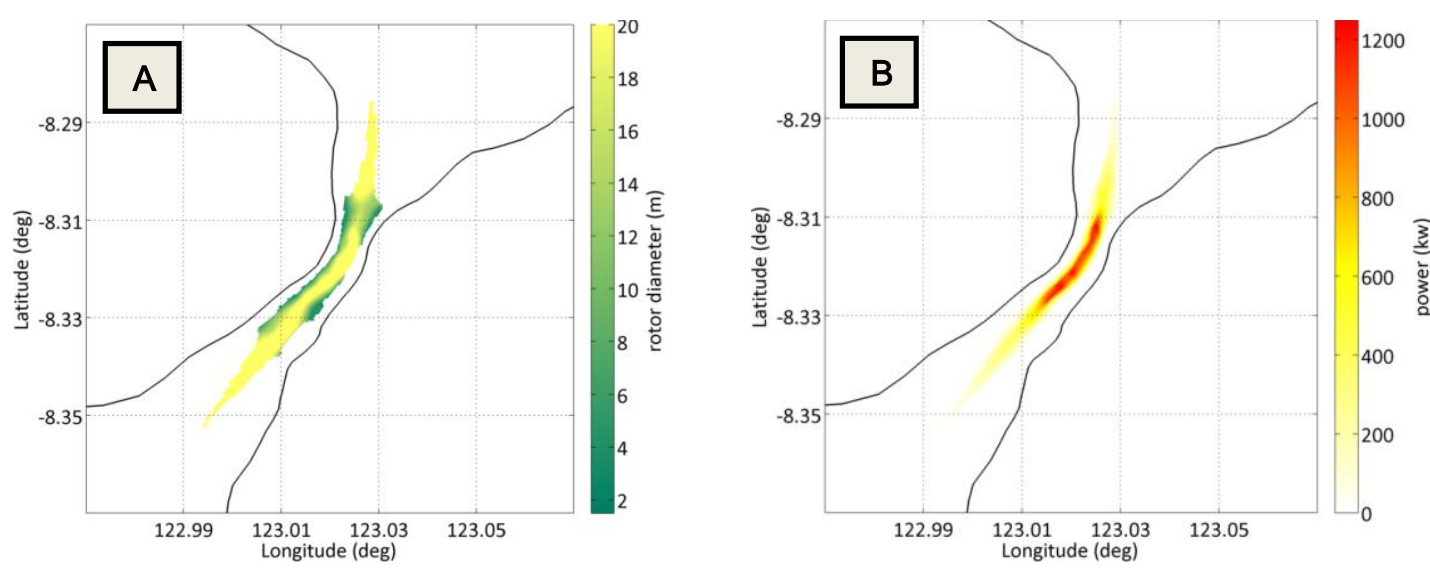

Figure 7. Spatial variation of the applicable tidal turbine rotor diameters (A) and of average extractable electric power with the tidal turbines (B) at the Strait of Larantuka

\begin{tabular}{|c|c|c|c|c|c|c|c|}
\hline & & & & Cut-in velo & $y=1.0 \mathrm{~m} / \mathrm{s}$ & Cut-in velo & $y=0.5 \mathrm{~m} / \mathrm{s}$ \\
\hline & Strait & $\begin{array}{c}\text { Max kinetic } \\
\text { power } \\
\text { density } \\
\left(\mathrm{kW} / \mathrm{m}^{2}\right)\end{array}$ & $\begin{array}{c}\text { Max } \\
\text { extractable } \\
\text { power by a } \\
\text { turbine } \\
\text { (kW) }\end{array}$ & $\begin{array}{c}\text { Suitable } \\
\text { area }\left(\mathrm{km}^{2}\right)\end{array}$ & $\begin{array}{c}\text { Total } \\
\text { extractable } \\
\text { power } \\
(\mathrm{MW})\end{array}$ & $\begin{array}{c}\text { Suitable } \\
\text { area }\left(\mathrm{km}^{2}\right)\end{array}$ & $\begin{array}{c}\text { Total } \\
\text { extractable } \\
\text { power } \\
(\mathrm{MW})\end{array}$ \\
\hline 1 & Bali & 14.75 & 1,459 & 23 & 462 & 104 & 1,045 \\
\hline 2 & Larantuka & 10.20 & 1,250 & 3 & 199 & 6 & 299 \\
\hline 3 & Boling & 3.49 & 430 & 36 & 593 & 106 & 736 \\
\hline 4 & Alas & 3.07 & 396 & 104 & 1,261 & 403 & 2,258 \\
\hline 5 & Lombok & 2.36 & 236 & 53 & 754 & 114 & 865 \\
\hline 6 & Sunda & 1.56 & 165 & 11 & 107 & 145 & 335 \\
\hline 7 & Badung & 1.52 & 161 & 28 & 238 & 162 & 551 \\
\hline
\end{tabular}

\section{CONCLUSIONS and OUTLOOK}

Tidal stream resource assessments are done for the straits between Indian Ocean and inner Indonesian seas. Energy hotspots are determined considering the available power and site characteristics. Applicable rotor diameters within the energy hotspots are defined and diameters ranging between $1.5 \mathrm{~m}$ and $20 \mathrm{~m}$ resulted. Spacing among the units is set to minimize the interferences. Power potentials are estimated considering typical power curves. The results obtained showed that the straits in question have tremendous potential for the production of ocean renewable energy. Current velocities are up to $3-4 \mathrm{~m} / \mathrm{s}$ and the power density at some locations can exceed $10 \mathrm{~kW} / \mathrm{m}^{2}$. Selected sites have been ranked based on the level of power density, and highest power densities are observed in the Strait of Larantuka. For each site, total tidal stream energy resource is estimated and spatial variation of the average exploitable electric power is determined. Although the Strait of Larantuka has highest power densities, it was seen that Alas Strait has the biggest potential for energy production, mainly as a consequence of its bigger energy hotspot size. According to the preliminary assessments, power production at the straits is likely to exceed previous predictions reaching around 4,800MW. Investigations accounting for other coastal uses, environmental, economic and social impacts are currently underway.

\section{ACKNOWLEDGMENTS}

This study is funded by the German Ministry of Education and Research under grant number 03F0646A. Bathymetric data provided by the Indonesian Agency "Badan Informasi Geospasial (BIG)" is highly appreciated. We are also grateful to the Indonesian "Agency for the Assessment and Application of Technology (BPPT)" for supporting the instalation and maintenance of the measuring devices in Larantuka. 


\section{REFERENCES}

Electric Power Research Institute (2006): Methodology for Estimating Tidal Current Energy Resources and Power Production by Tidal In-Stream Energy Conversion (TISEC) Devices, USA.

The European Marine Energy Center Ltd. (2009): Assessment of Tidal Energy Resource, UK.

Gordon, A.L. (2005): Oceanography of the Indonesian Seas and Their Throughflow, Oceanography, vol. 18, pp. 14-27.

Ray, R.D., Egbert, G.D., Erofeeva, S.Y. (2005): A Brief Overview of Tides in the Indonesian Seas, Oceanography, vol. 18, pp. 74-79.

Asif, M., Muneer, T. (2007): Energy supply, its demand and security issues for developed and emerging economies, Renewable and Sustainable Energy Reviews, ELSEVIER, vol. 11, pp.138826.

Defne, Z., Haas, K.A., Fritz, H.M. (2011): GIS based multi-criteria assessment of tidal stream power potential: A case study for Georgia, USA, Renewable and Sustainable Energy Reviews, ELSEVIER, vol. 15, pp. 2310-2321.

Mayer, B., Damm, P.E. (2012): The Makassar Strait throughflow and its jet, Journal of Geophysical Research, vol. 117, C07020.

Orhan, K., Mayerle, R., Pandoe, W.W. (2015): Assessment of energy production potential from tidal stream currents in Indonesia, Energy Procedia, ELSEVIER, vol. 76, pp. 7-16.

Uihlein, A., Magagna, D. (2016): Wave and tidal current energy - A review of the current state of research beyond technology, Renewable and Sustainable Energy Reviews, ELSEVIER, vol. 58, pp.1070-1081. 